\title{
Identification and Characterization of a Soybean Ethylene-Responsive Element-Binding Protein Gene Whose mRNA Expression Changes During Soybean Cyst Nematode Infection
}

\author{
Mitra Mazarei, ${ }^{1}$ David P. Puthoff, ${ }^{1}$ Jennifer K. Hart, ${ }^{1}$ Steven R. Rodermel, ${ }^{2}$ and Thomas J. Baum ${ }^{1}$ \\ ${ }^{1}$ Department of Plant Pathology, and ${ }^{2}$ Department of Botany, lowa State University, Bessey Hall, Ames, IA 50011 U.S.A. \\ Submitted 6 November 2001. Accepted 8 February 2002.
}

\begin{abstract}
Ethylene-responsive element-binding proteins (EREBPs) are members of a family of plant transcription factors. Conserved EREBP domains of these proteins bind to the GCC box, an ethylene-responsive promoter element found in many pathogenesis-related (PR) genes. Using degenerate primers to the EREBP domain from diverse plant species, an $E R E B P$ homolog was isolated from a soybean cDNA library. Gel mobility-shift assays revealed that the translation product of this cDNA bound specifically to GCC box sequences. We, therefore, named this gene Glycine max ethylene-responsive element-binding protein 1 (GmEREBP1), i.e., a gene coding for the first confirmed GCC box-binding protein of soybean. GmEREBP1 mRNA abundance was analyzed by RNA blot hybridizations in soybean roots and shoots of cultivars Corsoy 79 and Hartwig, which are susceptible and resistant, respectively, to the soybean cyst nematode (Heterodera glycines). These analyses revealed that $G m E R E B P 1$ is expressed in a root-preferential manner and that GmEREBP1 mRNA abundance is changed after $H$. glycines infection. GmEREBP1 mRNA abundance decreased in infected (susceptible) 'Corsoy 79' roots, whereas it increased in abundance in infected (resistant) 'Hartwig' roots. Furthermore, ethephon treatment repressed GmEREBP1 mRNA accumulation in both cultivars, whereas wounding increased expression in both cultivars. These changes in mRNA steady-state levels suggest that $G m E R E B P 1$ plays a role in soybean- $\mathrm{H}$. glycines interactions.
\end{abstract}

Additional keywords: AP2, Arabidopsis thaliana, DNA-binding domain, syncytium.

Transcription factors often comprise families of related proteins that share a homologous DNA-binding domain. An example is the ethylene-responsive element-binding protein (EREBP) group, which is a member of the APETALA2 (AP2)/EREBP gene family of plant transcription factors. These proteins are distinguished by the presence of a DNA-binding domain (the EREBP domain) that is highly conserved in size (59 to 60 amino acids) and in sequence among higher plants (Riechmann and Meyerowitz 1998). EREBP-domain-containing genes have

Corresponding author: Thomas J. Baum; Telephone: +1-515-294-2398; Fax: +1-515-294-9420; E-mail: tbaum@ iastate.edu

Nucleotide sequence data reported are available in the GenBank/EMBL/ DDBJ databases under the accession number AF357211. been characterized in tobacco (Ohme-Takagi and Shinshi 1995; Park et al. 2001), tomato (Zhou et al. 1997), Arabidopsis (Büttner and Singh 1997; Finkelstein et al. 1998; Fujimoto et al. 2000; Kagaya et al. 1999; Liu et al. 1998; Okamuro et al. 1997; Solano et al. 1998; Stockinger et al. 1997; Wilson et al. 1996), and periwinkle (Menke et al. 1999; van der Fits and Memelink 2000). It has been directly demonstrated that some of these EREBPs bind to the GCC box, a conserved ethyleneresponsive promoter element found in many defense-related genes. The GCC box is necessary and sufficient for ethylene regulation of plant genes (Stepanova and Ecker 2000).

We previously used differential display of mRNA to isolate cDNA clones corresponding to mRNA species that show altered abundance during the early stages of interaction between the soybean cyst nematode (Heterodera glycines) and soybean (Glycine max) and between the sugar beet cyst nematode $(H$. schachtii) and Arabidopsis thaliana (Hermsmeier et al. 1998, 2000). In these studies, we showed that the mRNA abundance of the EREBP gene RAP2.3 (also called AtEBP [Riechmann and Meyerowitz 1998]) decreased in Arabidopsis roots infected with the sugar beet cyst nematode (Hermsmeier et al. 2000). The down regulation of $A t E B P / R A P 2.3$ in nematode-infected Arabidopsis roots prompted us to examine the possible role of EREBP-like genes in the soybean- $H$. glycines interaction.

The soybean cyst nematode is a sedentary obligate endoparasite that causes extensive damage to soybeans worldwide (Wrather et al. 2001a, 2001b). To complete the life cycle, infective second-stage juveniles (J2) enter host roots, migrate intracellularly, and initiate formation of specialized feeding sites called syncytia, which function as metabolic sinks to nourish the nematodes (Jones 1981). In susceptible cultivars, nematodes depend entirely on functional syncytia to acquire nutrients to develop into reproductive adult males or females. $H$. glycines $\mathrm{J} 2$ also penetrate roots of resistant cultivars and initiate syncytia. However, resistance soon manifests itself by a degeneration of the young syncytia and a failure of the nematode to develop further (Endo 1991; Kim and Riggs 1992; Kim et al. 1987; Mahalingam and Skorupska 1996).

Syncytium formation and maintenance are thought to be mediated through nematode secretions and are accompanied by changes in plant gene expression (Davis et al. 2000; Williamson and Hussey 1996). Identification and characterization of host genes that change expression and, therefore, are potentially involved in the nematode-plant interaction might prove to be highly informative. Studies by Hermsmeier and colleagues (1998), Mahalingam and colleagues (1999), and Vaghchipawala and colleagues (2001) identified several soy- 
bean cDNAs whose expression is changed during soybean $-H$. glycines interactions. In the current report, we describe the isolation and characterization of a soybean EREBP gene preferentially expressed in roots and show that its mRNA abundance changes following $H$. glycines infection, ethephon treatment, and wounding in a $H$. glycines-susceptible (Corsoy 79) and a -resistant (Hartwig) soybean cultivar.

\section{RESULTS}

Isolation of a soybean EREBP-like gene.

Using degenerate primers to the conserved EREBP domain of diverse plant EREBPs, a 180-bp polymerase chain reaction (PCR) product was amplified from a soybean cDNA library that was prepared from $H$. glycines-infected susceptible soybean roots (discussed below). Screening of approximately 350,000 plaques from the cDNA library with the PCR fragment yielded four clones corresponding to one soybean mRNA whose predicted translation product contained the EREBP domain. The longest cDNA clone was $752 \mathrm{bp}$, excluding the $3^{\prime}$ poly(A) stretch (GenBank accession no. AF357211). This cDNA appeared to be full length because (i) it contained an open reading frame initiated by an ATG, (ii) it was terminated by a poly(A) tail, and (iii) its size corresponded to the transcript size determined by mRNA gel blot analysis (discussed below).

The predicted translation product of the open reading frame contains 202 amino acids (Fig. 1) and codes for a protein with a molecular mass of $23 \mathrm{kDa}$ and a $\mathrm{pI}$ of 7.01. The protein has a central 60-amino acid EREBP domain that is rich in basic amino acid residues, a characteristic typical of the DNA-binding domains of many transcription factors (Latchman 1995). As illustrated by the sequence alignment in Figure 2, the soybean sequence has a high degree of similarity to the EREBP domains of proteins from other plant species, with the highest similarity to the tobacco EREBP-1 and EREBP-2, the Arabidopsis AtERF1 and AtERF2, and the tomato Pti4 proteins. The soybean EREBP domain also has two conserved segments, termed the YRG and the RAYD elements (Okamuro et al. 1997) (Fig. 2). The YRG element contains a conserved amino acid sequence motif called the WAAEIRD box, which is thought to be involved in regulating the specificity of DNA binding (Okamuro et al. 1997). The RAYD element contains a central region with an $\alpha$-helix amphipathic character that is also thought
1 ATACAGTGAGCAAAGTTAGCTGAAAATTAAAACATGGTTTCCGCCACCGTGGATTCCGAT

$\begin{array}{lllllllll}M & V & S & A & T & V & D & S & D\end{array}$

9

29

49

69

$\begin{array}{llllllllllllllllllll}D & S & G & N & I & A & F & R & S & E & D & A & T & A & V & V & A & R & D & H\end{array}$

181 GATTCAGGGAACATTGCTTTCCGAAGTGAGGATGCAACGGCTGTGGTAGCGCGTGATCAT

$\begin{array}{llllllllllllllllllll}A & P & P & T & W & K & H & Y & R & G & V & R & R & R & P & W & G & K & F & A\end{array}$

241 GCGCCACCAACATGGAAGCATTACAGAGGGGTGAGGCGTAGACCGTGGGGAAAGTTTGCG \begin{tabular}{llllllllllllllllllll}
$A$ & $\mathbf{E}$ & $\mathrm{I}$ & $\mathbf{R}$ & $\mathrm{D}$ & $\mathrm{P}$ & $\mathrm{K}$ & $\mathrm{K}$ & $\mathrm{N}$ & $\mathrm{G}$ & $\mathrm{A}$ & $\mathbf{R}$ & $\mathrm{V}$ & $\mathrm{W}$ & $\mathrm{L}$ & $\mathrm{G}$ & $\mathrm{T}$ & $\mathrm{Y}$ & $\mathrm{D}$ & $\mathrm{T}$ \\
\hline
\end{tabular}

301 GCCGAGATTAGGGATCCAAAGAAGAACGGAGCTAGGGTTTGGCTTGGCACGTATGATACC \begin{tabular}{llllllllllllllllllll}
$E$ & $\mathbf{E}$ & $\mathrm{K}$ & $\mathrm{A}$ & $\mathrm{A}$ & $\mathrm{L}$ & $\mathrm{A}$ & $\mathrm{Y}$ & $\mathrm{D}$ & $\mathrm{K}$ & $\mathrm{A}$ & $\mathrm{A}$ & $\mathrm{F}$ & $\mathrm{K}$ & $\mathrm{M}$ & $\mathrm{R}$ & $\mathrm{G}$ & $\mathrm{Q}$ & $\mathrm{K}$ & $\mathrm{A}$ \\
\hline
\end{tabular} \begin{tabular}{llllllll|lllllllllllll}
$\mathrm{K}$ & $\mathrm{L}$ & $\mathrm{N}$ & $\mathrm{F}$ & $\mathrm{P}$ & $\mathrm{H}$ & $\mathrm{L}$ & $\mathrm{I}$ & $\mathrm{D}$ & $\mathrm{S}$ & $\mathrm{D}$ & $\mathrm{N}$ & $\mathrm{S}$ & $\mathrm{D}$ & $\mathrm{E}$ & $\mathrm{L}$ & $\mathrm{S}$ & $\mathrm{E}$ & $\mathrm{P}$ & $\mathrm{V}$
\end{tabular}

421 AAGCTGAATTTCCTCATCTTATTGATTCCGACAATTCCGATGAATTGTCGGAGCCAGTA

\begin{tabular}{llllllllllll|llllllll}
$M$ & $M$ & $T$ & $T$ & $S$ & $K$ & $R$ & $S$ & $I$ & $I$ & $E$ & $I$ & $S$ & $S$ & $P$ & $S$ & $S$ & $S$ & $C$ & $S$ \\
\hline
\end{tabular}

481 ATGATGACAACTTCCAAGCGAAGTTTGTTAGAAATTTCATCACCGTCGTCCTCGTGTTCA $<-------->$ \begin{tabular}{lllllllllllllllllllllll}
\hline$D$ & $D$ & $S$ & $S$ & $E$ & $S$ & $Q$ & $G$ & $T$ & $K$ & $R$ & $R$ & $K$ & $S$ & $L$ & $A$ & $E$ & $L$ & $L$ & $N$
\end{tabular}

541 GATGATAGCTCAGAATCACAAGGGACAAAGAGGAGGAAGAGCCTGGCTGAACTACTGAAT

601 AAATTAGCCAAGAATAGAAGCCAAGTCAAGgTGGAATGTTGAAGTGGCTAGAGGAATATG

661 CATGTTGTACAATTTGATCAATCATTAATATGAGACTTCAACGATTGTAATGTAATCTGG

721 TGTTCATAGAATTAATGCAATTTTGTTCCCAAAAAAAAAAA

Fig. 1. Nucleotide and predicted amino acid sequences of the soybean ethylene-responsive element-binding protein (EREBP)-like cDNA clone (GenBank accession no. AF357211). The soybean EREBP-like cDNA nucleotide sequence begins with a short 5 '-untranslated region and ends with a poly(A) sequence downstream from the stop codon (indicated by an asterisk). The predicted amino acid sequence is shown directly above the nucleotide sequence. The conserved EREBP domain is underlined. Arrows indicate the putative nuclear localization signal, KRRK. The acidic domain (from amino acids 138 to 147) and serine-rich region (from amino acids 162 to 175) are marked by boxes. 
to play a role in DNA binding, although this role has yet to be clearly defined (Okamuro et al. 1997).

Comparison of the soybean EREBP-like protein to EREBPs from other plant species revealed that the position of the soybean EREBP domain within the protein is almost identical to the EREBP domain position in the AtEBP/RAP2.3 protein (data not shown), i.e., the protein that was previously found to be down-regulated in A. thaliana roots infected by $H$. schachtii (Hermsmeier et al. 2000). Furthermore, while EREBP domains are highly conserved within and among plant species, the amino acid sequences flanking these domains are highly variable, with the exception that they contain short, conserved sequence elements that are consistent with their function as transcription factors. In the case of the soybean EREBP-like protein, these sequence elements include a putative nuclear localization signal (NLS) that is located in the C-terminal region of the protein (Fig. 1). This NLS is composed of a short cluster of the basic amino acid residues KRRK (Raikhel 1992). Also toward the C terminus, the protein contains a serine-rich sequence and an acidic domain, both of which are hallmarks of transcription activation domains (Riechmann and Meyerowitz 1998).

Although we detected only one type of EREBP-like cDNA in our library screening, we were interested in determining whether there are closely related genes in the soybean genome. DNA blot analysis of EcoRI-digested soybean genomic DNA showed that two DNA fragments hybridized, one strongly and the other weakly, when the blot was probed with our EREBP cDNA (Fig. 3). Because the EREBP-like cDNA does not contain an EcoRI site, this observation could be explained by the presence of at least one additional similar EREBP-like gene in soybean. On the other hand, the presence of an additional hybridizing band could be explained by an EcoRI restriction site in putative introns of the EREBPlike gene, which we did not discern. However, consistent with the presence of one closely related gene is our finding that the soybean expressed sequence tag (EST) collection contains one EREBP-like sequence similar to the one we iso- lated, in addition to several other considerably less well-conserved EREBP-like sequences. The most similar EREBP-like sequence was represented by an EST (GenBank accession no. AI495036) isolated from a root cDNA library. While the EREBP domain of this cDNA has $82 \%$ identity to the EREBP domain of the soybean EREBP-like cDNA identified in this study, it is completely unrelated in the regions flanking the EREBP domain. Interestingly, the mRNA corresponding to this latter $E R E B P$-like cDNA clone, which is larger in size (901 bases) than our soybean EREBP-like cDNA, was not detected in our RNA blot analyses (discussed below), indicating a very weak expression, at least in the tissues analyzed in this study.

\section{Binding of the soybean EREBP-like protein to the GCC box.}

Gel mobility-shift assays were performed to analyze whether the soybean EREBP-like protein binds to the GCC box ethyleneresponsive promoter element. For these experiments, the coding region of the soybean $E R E B P$-like gene was overexpressed in Escherichia coli and purified. Purified proteins from E. coli cultures harboring the appropriate vector without the EREBP gene insert were isolated and served as a control (pET control). Oligonucleotides were synthesized that represent the GCC and mutated GCC (mGCC) probes used by Ohme-Takagi and Shinshi (1995) to show binding of tobacco EREBP proteins to the GCC box (discussed below). As shown in Figure 4A, the soybean EREBP homolog caused a mobility shift in the radioactively labeled GCC probe. This shift was specific to the soybean protein and did not occur in the pET control. Furthermore, when a mutated version of the GCC box (mGCC) was used in the assay, the mobility shift was not observed (Fig. 4A).

Competition experiments were conducted to examine the specificity of the mobility shift. In these experiments, the purified soybean EREBP homolog was mixed with the radiolabeled GCC probe, and the unlabeled competitor (either the GCC probe or the mGCC probe) was then added to the mixture

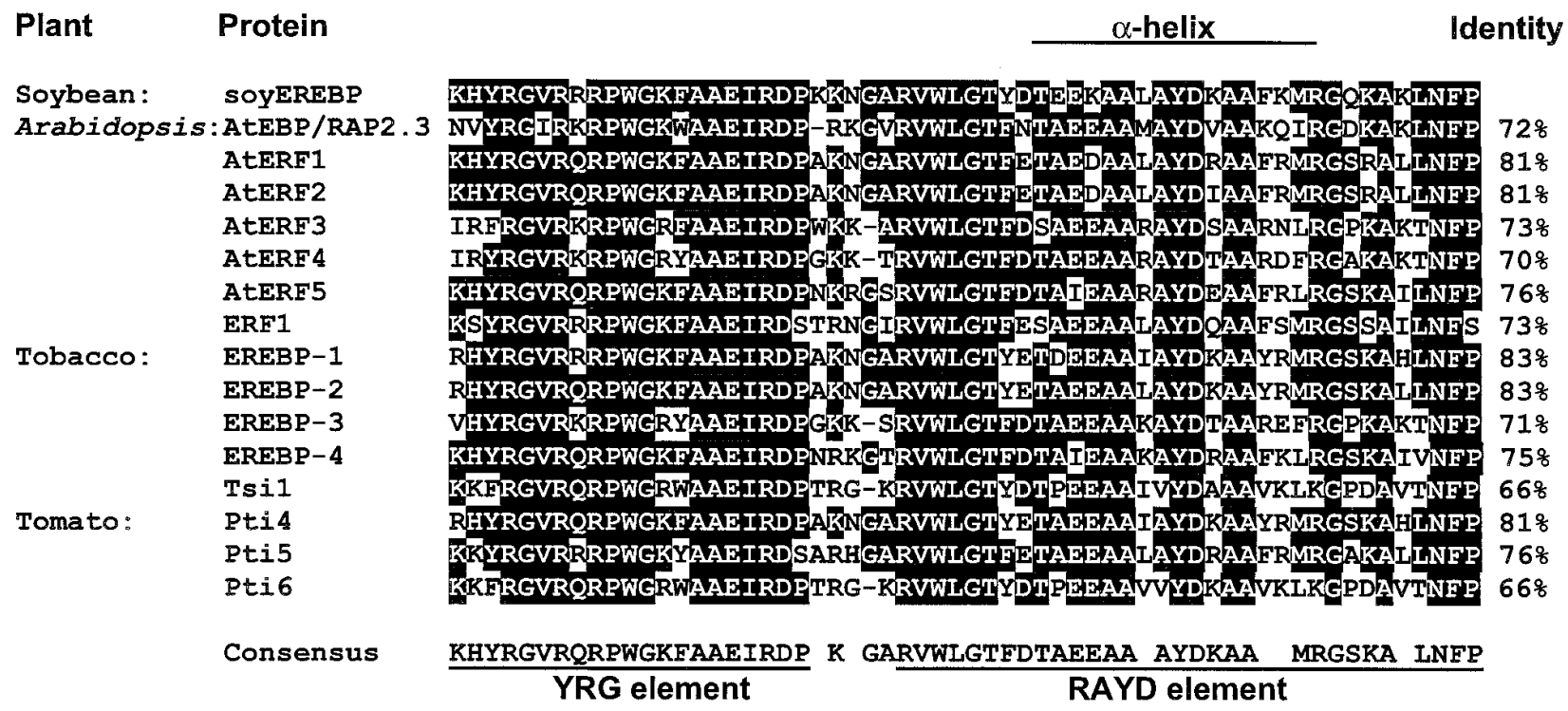

Fig. 2. Alignment of the soybean ethylene-responsive element-binding protein (EREBP)-like (soyEREBP) domain with EREBP domains from other plant proteins. Proteins included in this comparison are from the following genes: Arabidopsis thaliana AtEBP/RAP2.3 (GenBank accession nos. Y09942/AF003096), AtERF1 to AtERF5 (GenBank accession nos. AB008103 through AB008107, respectively), ERF1 (GenBank accession no. AF076278), tobacco EREBP-1 to EREBP-4 (GenBank accession nos. D38123 through D38126, respectively), Tsi1 (GenBank accession no. AF058827), and tomato Pti4 to Pti6 (GenBank accession nos. U89255 through U89257, respectively). Sequences were aligned with the CLUSTAL-W program (Thompson et al. 1994). Black boxes indicate amino acid residues identical to the consensus sequence shown below the alignment. Numbers on the right indicate the percentage of amino acid identity of each EREBP domain to the soybean EREBP domain. Dashes indicate gaps in the amino acid sequences used to optimize the alignment. The YRG and RAYD elements are indicated with solid lines below the consensus sequence. The region predicted to form an amphipathic $\alpha$-helix is indicated by a line above the alignments. 
in varying amounts. Figure $4 \mathrm{~B}$ shows that as little as $6 \mathrm{ng}$ of unlabeled GCC probe, which represents an approximately equal ratio of labeled GCC to unlabeled GCC, competed for the binding of the labeled probe. As the levels of unlabeled GCC increased, the amount of bound labeled probe decreased. When the ratio of unlabeled to labeled GCC probe reached approximately 100:1, virtually no labeled probe was bound. When the unlabeled mGCC probe was used as the competitor, no binding competition was observed, even at a ratio of 100:1 unlabeled mGCC to labeled GCC (Fig. 4B). Taken together, these observations demonstrate that there is specific binding of the soybean EREBP-like protein to GCC box sequences. Given the observed sequence similarity of this protein to known EREBP sequences and its specific binding to a GCC box probe, we propose the name $\underline{G}$ lycine $\underline{\max }$ ethylene-responsive elementbinding protein $\underline{1}$ (GmEREBP1) for this cDNA.

\section{Expression of $G m E R E B P 1$.}

The expression of GmEREBP1 was analyzed at the mRNA level by blot hybridizations to RNA from roots and shoots of the two soybean cultivars, Corsoy 79 and Hartwig, which are susceptible and resistant, respectively, to $H$. glycines. Furthermore, changes in GmEREBP1 mRNA abundance following $H$. glycines infection were assessed in both soybean cultivars. The dynamics of nematode infection and development in roots of susceptible and resistant soybean plants were determined by staining the infected roots for nematodes at varying time points postinoculation. Nematode penetration into soybean roots was equally effective in both the susceptible and resistant soybean cultivars, since equal numbers of nematodes were observed inside the inoculated roots of both cultivars (Table 1). Assessment of nematode development in roots of the two soybean cultivars up to 30 days postinoculation showed that all juveniles in the roots of the resistant 'Hartwig' failed to mature. On the other hand, nematodes that infected susceptible 'Corsoy 79' roots developed into adult males and females, indicating a normal progression of the $H$. glycines life cycle (data not shown). These results demonstrated that, under our conditions, synchronous nematode invasion was achieved in both soybean culti-

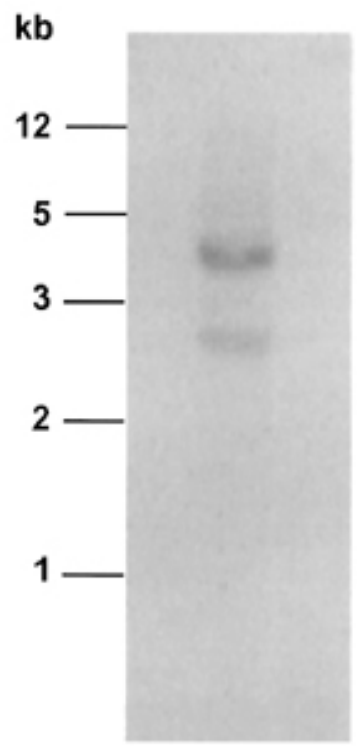

Fig. 3. Southern blotting of soybean genomic DNA using the soybean ethylene-responsive element-binding protein (EREBP)-like cDNA as a probe. Soybean genomic DNA (10 $\mu \mathrm{g}$ per lane) was digested with EcoRI and electrophoresed through a $1 \%$ agarose gel. The DNA blot was hybridized with the soybean EREBP-like cDNA. Numbers at left are molecular length markers in kilobase pairs $(\mathrm{kb})$. vars and that the selected soybean cultivars Corsoy 79 and Hartwig are truly susceptible and resistant, respectively, to the nematode population chosen in this study.

RNA blot analyses were performed using total RNA obtained from roots and shoots of $H$. glycines-infected or uninfected Corsoy 79 (susceptible) and Hartwig (resistant) soybean cultivars harvested at 1,3 , and 6 days postinoculation. Total RNA was prepared from pooled root or shoot tissues from eight plants for each treatment. The intensities of hybridization signals were measured by phosphorimage analyses. Representative blots are shown in Figure 5A. Similar results were obtained in three other experiments. The GmEREBP1 transcript was only weakly detectable in shoot tissues but was readily detectable in total RNA from roots of both susceptible and resistant soybeans as a hybridizing band with a size corresponding to the longest cDNA sequence identified by us (approximately 760 bases). We observed altered mRNA steady-state levels of GmEREBP1 after $H$. glycines infection in both the susceptible and resistant cultivars (Fig. 5A and B). GmEREBP1 mRNA abundance decreased in susceptible roots after $H$. glycines infection, while it increased in infected resistant roots. As a control, a soybean actin probe (Nagao et al. 1981), which we have previously shown to be constitutively expressed during the early H. glycines infection stages (Hermsmeier et al. 1998), detected approximately equal amounts of mRNA at each time point.

Because the soybean GmEREBP1 protein binds to the GCC box sequence (Fig. 4), we analyzed ethylene effects on the mRNA steady-state levels of GmEREBP1 in both soybean cultivars. Total RNA was prepared from pooled roots of 10 ethephon-treated or mock-treated soybean plants. Representative blots are shown in Figure 6A. Similar results were obtained in a total of three experiments. RNA gel blot analyses revealed that, in soybean roots of both cultivars, the transcript level of GmEREBP1 decreased after treatment with ethephon.

The effect of mechanical wounding on GmEREBP 1 mRNA abundance in roots of both soybean cultivars was analyzed by RNA blot analysis by using total RNA isolated from pooled roots of 10 wounded or mock-treated plants. As shown in Figure $6 \mathrm{~B}$, wounding moderately increased GmEREBP 1 expression in both cultivars. This experiment was repeated twice, and similar results were obtained.

\section{DISCUSSION}

A number of EREBPs have been characterized from several plant species. These include EREBP-1, EREBP-2, EREBP-3, and EREBP-4 (Ohme-Takagi and Shinshi 1995) and Tsi1 (Park et al. 2001) from tobacco; Pti4, Pti5, and Pti6 from tomato (Zhou et al. 1997); TINY (Wilson et al. 1996), AtEBP (Büttner and Singh 1997), CBF1 (Stockinger et al. 1997), RAP2.1 to RAP2.6 and RAP2.8 to RAP2.12 (Okamuro et al. 1997), ABI4 (Finkelstein et al. 1998), DREB1 and DREB2 (Liu et al. 1998), ERF1 (Solano et al. 1998), RAV1 and RAV2 (Kagaya et al. 1999), and AtERF1, AtERF2, AtERF3, AtERF4, and AtERF5 (Fujimoto et al. 2000) from A. thaliana; and ORCA1, ORCA2, and ORCA3 (Menke et al. 1999; van der Fits and Memelink 2000) from periwinkle. In this report, we isolated and characterized an EREBP gene from soybean (GmEREBP1). This gene belongs to the EREBP branch of the $A P 2 / E R E B P$ gene family of plant transcription factors, because the encoded protein contains a single copy of the conserved DNA-binding domain (i.e., the EREBP domain) in contrast to AP2-like proteins, which contain two copies of the DNA-binding domain (Riechmann and Meyerowitz 1998). Furthermore, the GmEREBP1 protein possesses the WAAEIRD domain, a motif involved in determining the specificity of DNA binding, which is not found in AP2-like proteins (Riechmann and Meyerowitz 1998). 
The EREBP domain of GmEREBP1 shows the strongest sequence similarity to the tobacco EREBP-1 and EREBP-2, the Arabidopsis AtERF1 and AtERF2, and the tomato Pti4 proteins. Despite this strong conservation, GmEREBP1 sequences flanking the EREBP domain show no detectable similarity to any of the other proteins. It is also interesting to note that the position of the EREBP domain within the GmEREBP1 protein is almost identical to that of the AtEBP/RAP2.3 protein but different from that of other EREBPs. These observations suggest the presence of multiple forces driving EREBP evolution, leading to the conservation of the EREBP domain sequence and a diversification of the regions flanking it.

Some EREBP-like proteins have been demonstrated to bind to the GCC box in vitro and, thus, are bona fide EREBPs. These include the tobacco EREBPs (Ohme-Takagi and Shinshi 1995) and Tsi1 (Park et al. 2001); the tomato Pti4, Pti5, and Pti6 proteins (Gu et al. 2000; Zhou et al. 1997); and the A. thaliana AtEBP/RAP2.3 (Büttner and Singh 1997), ERF1 (Solano et al. 1998), and AtERF (Fujimoto et al. 2000) proteins. Our gel mobility-shift experiments revealed that GmEREBP1 binds to the GCC box, indicating that it is an EREBP. It has yet to be determined whether GmEREBP1 has other specificities.

Several GCC box-binding proteins have been shown to participate in signal transduction events leading from pathogen infection to defense response. For example, in tomato, the tomato Pti4 protein interacts with the Pto resistance gene product (a kinase), resulting in the phosphorylation of Pti4, which in turn enhances expression of GCC box-containing pathogenesisrelated (PR) genes in tomato (Gu et al. 2000; Zhou et al. 1997). Consistent with this observation, the concomitant overexpression of Pto and Pti4 in tomato resulted in the induction of GCC box-containing PR genes ( $\mathrm{Gu}$ et al. 2000). In the case of the tomato-Pseudomonas syringae interaction, transcripts of the tomato EREBP genes Pti4 and Pti5 are elevated after pathogen attack in both resistant and susceptible responses ( $\mathrm{Gu}$ et al. 2000; Thara et al. 1999). The tobacco EREBP-2 protein specifically interacts with the tomato Pto kinase in yeast twohybrid assays. Tobacco EREBP-1 mRNA is also up-regulated during the resistant response of the host to the $P$. syringae bacterial pathogen (Zhou et al. 1997). Tobacco EREBP-2 and EREBP-3, as well as tomato Pti4, Pti5, and Pti6 proteins, have also been shown to interact with nitrilase, a cytoplasmic enzyme involved in auxin biosynthesis. Auxin, in turn, is involved in pathogenesis-induced defense gene expression (Xu et al. 1998). A recent study by Park and colleagues (2001) demonstrated that overexpression of the Tsil EREBP-like gene in tobacco plants induced expression of several PR genes, resulting in improved resistance against pathogen attack.

In Arabidopsis, Solano and colleagues (1998) reported that overexpression of the ERF1 EREBP-like gene in an $A$. thaliana line harboring a bean PR gene (chitinase) promoterreporter gene fusion resulted in activation of the chitinase promoter. Experiments involving AtEBP, i.e., the gene whose protein product shows the same EREBP domain position as GmEREBP1 and whose mRNA abundance is altered following A. thaliana infection with a cyst nematode (Hermsmeier et al. 2000), have shown that the AtEBP protein, in addition to its GCC box-binding activity, interacts with an ocs element-binding protein, a basic leucine-zipper plant transcription factor involved in the expression of plant defense genes (Büttner and Singh 1997). Taken together, these observations demonstrate that a number of EREBP genes in diverse species participate in signal transduction events leading to the manifestation of plant defense.

Our mRNA abundance change data give rise to very interesting speculations. In both cultivars, ethephon treatment, which increases available ethylene, resulted in decreased GmEREBP1 mRNA steady-state levels. Wounding, on the other hand, in- creased GmEREBP $1 \mathrm{mRNA}$ abundance in both cultivars. Therefore, it seems that both cultivars behave the same with regard to their regulation of $G m E R E B P 1$ expression in response to these stimuli.

Wound induction of EREBP genes is a frequently reported feature in several plant species (Fujimoto et al. 2000; Gu et al. 2000; Park et al. 2001; Thara et al. 1999). Down regulation by ethylene, on the other hand, has been reported only for very few EREBP genes (Johnson and Ecker 1998). Therefore, GmEREBP1 appears somewhat unusual in its response to ethylene. It would be particularly interesting to know in this connection whether GmEREBP 1 acts as a transcriptional inducer or repressor after binding to the GCC box, because both activities

A

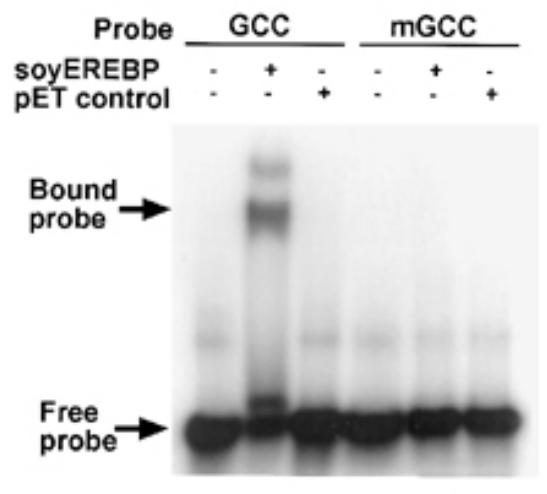

B

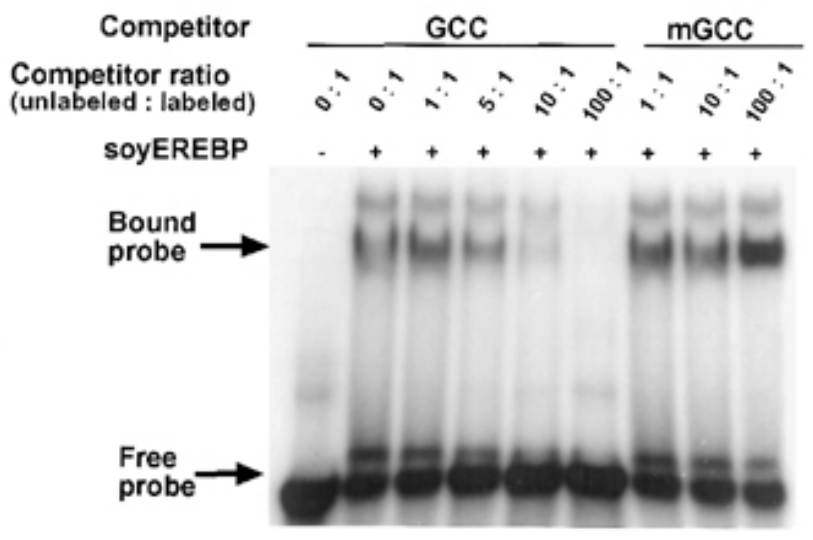

Fig. 4. Binding of the soybean ethylene-responsive element-binding protein (EREBP)-like (soyEREBP) protein to the GCC box $\mathbf{A}$, without and $\mathbf{B}$, with competitor. A, The soyEREBP protein was overexpressed in Escherichia coli and purified under native conditions. Purified soyEREBP protein or the negative control (pET control) was mixed (designated by "+") with the ${ }^{32} \mathrm{P}$-labeled GCC box probe (GCC) or a mutated version (mGCC) and fractionated using native polyacrylamide gel electrophoresis. DNA binding is visualized by the presence of bound probe. SoyEREBP protein causes a mobility shift from free probe to bound probe, while the pET control protein does not cause a mobility shift. Neither protein causes a mobility shift when the mutated GCC box (mGCC) is used as a probe. B, Mobility-shift assays were conducted as described above, with the addition of an unlabeled probe as a competitor. All lanes contain labeled GCC probe, and lanes marked with "+" contain purified soyEREBP protein. One of two unlabeled competitor probes was added in the ratio given above each lane. As little as $6 \mathrm{ng}$ of unlabeled GCC probe (1:1, unlabeled/ labeled) can compete for the binding site of soyEREBP protein, and the addition of $600 \mathrm{ng}$ (100:1, unlabeled/labeled) of unlabeled GCC probe completely competes for the binding site of soyEREBP protein. In contrast, $600 \mathrm{ng}$ (100:1, unlabeled/labeled) of the mutated GCC box (mGCC) does not compete for the binding site of the soyEREBP protein. 
have been reported for EREBP genes in other species (Fujimoto et al. 2000; Liu et al. 1998; Menke et al. 1999; Ohta et al. 2000; van der Fits and Memelink 2000). Toward this goal, we determined that GmEREBP1 does not contain the repressor motif described for certain EREBPs by Ohta and colleagues (2001).

Of most interest to us is the fact that GmEREBP 1 mRNA abundance changes following $H$. glycines infection. Notably, mRNA levels changed in opposite directions in response to infection in the two cultivars used in this study, despite the fact that both cultivars behaved the same with regard to the frequency of nematode penetration, as well as under the other conditions tested (i.e., ethephon treatment and wounding). Plant-parasitic nematode infection has been reported to increase ethylene concentrations in infected host roots (Glazer et al. 1986). Assuming increased ethylene concentrations also in infected soybean roots, a down regulation of GmEREBP1 mRNA expression in the infected susceptible cultivar is explicable if one further assumes that the nematode-inflicted wounds do not generate enough of an up regulation of GmEREBP1 mRNA expression to override the ethylene effect. These assumptions do not, however, explain the up regulation of GmEREBP1 in the infected resistant soybean cultivar, because these tissues would be expected to behave similar to the susceptible cultivar with respect to ethylene and wounding. Consistent with this notion, ethylene increases after nematode infection were observed in susceptible as well as resistant cultivars of other plant species (Glazer et al. 1986; Volkmar 1991). Therefore, it is tempting to hypothesize that a stimulus involved in triggering resistance is responsible for the observed GmEREBP1 mRNA induction. In other words, given the known involvement of certain EREBPs in mediating resistance in other plants and pathosystems, our data make GmEREBP1 a strong candidate to test for its possible involvement in resistance signal transduction in the cultivar Hartwig.

Although GmEREBP1 mRNA steady-state level changes upon nematode infection are relatively small, these changes are very reproducible and, therefore, appear meaningful. Speculating on the biological relevance of mRNA abundance changes at this time, however, is premature because we do not know (i) in how many and in which root cells these changes occur, (ii) which downstream genes are transcriptionally regulated by GmEREBP1, and (iii) whether observed mRNA changes truly result in abundance changes of active GmEREBP1 protein. These questions and others have to be addressed in ongoing as well as future research projects.

One concern of this study was that the susceptible and the resistant soybean cultivars used are not isogenic. Therefore, the observed GmEREBP1 regulation during the susceptible and resistant interactions with $H$. glycines may be because of other, resistance-unrelated differences in the genetic backgrounds of both cultivars. This concern was alleviated when observing that both cultivars behaved the same with regard to GmEREBP1 regulation in response to ethephon treatment and wounding, indicating a similar regulation of certain stress responses in both

Table 1. Number of Heterodera glycines juveniles in roots of the soybean cultivars Corsoy 79 (susceptible) and Hartwig (resistant) at 1, 3, and 6 days postinoculation (dpi)

\begin{tabular}{lccc}
\hline Cultivar $^{\mathbf{a}}$ & $\mathbf{1} \mathbf{d p i}^{\mathbf{b}}$ & $\mathbf{3} \mathbf{d p i}^{\mathbf{b}}$ & $\mathbf{6} \mathbf{d p i}^{\mathbf{b}}$ \\
\hline Corsoy 79 & 84 & 146 & 191 \\
Hartwig & 78 & 154 & 186 \\
\hline
\end{tabular}

${ }^{a}$ Each plant was inoculated with 1,000 surface-sterilized H. glycines juveniles.

${ }^{b}$ Values are means of four replicates. Statistical analyses using a twosample $t$ test showed no significant difference between the number of nematodes in roots of the two soybean cultivars at each time point. cultivars. It appears, therefore, most likely that the observed differences in GmEREBP1 regulation in response to $H$. glycines are associated with the fact that both cultivars differ in their susceptibility to this pathogen. Unfortunately, we are not aware of suitable isogenic soybean cultivars differing in susceptibility to $H$. glycines, which would have allowed an unambiguous testing of this phenomenon. Nonetheless, our results provide a starting point for a more rigorous exploration of the role of this gene in soybean- $H$. glycines interactions.

\section{MATERIALS AND METHODS}

Isolation of the conserved EREBP domain from soybean.

Nucleotide sequences of cDNA clones containing the conserved EREBP DNA-binding domain isolated from several plant species were obtained via BLAST searches (Altschul et al. 1997), and sequences were aligned with the DNASIS program (Hitachi Software Engineering, San Bruno, CA, U.S.A.). These sequences included A. thaliana AtEBP (GenBank accession no. Y09942), tobacco EREBP-1 through EREBP-4 (GenBank accession nos. D38123, D38126, D38124, and D38125, respectively), tomato Pti4, Pti5, and Pti6 (GenBank accession nos. U89255, U89256, and U89257, respectively), a rice cDNA (GenBank accession no. AF190770), and a watermelon cDNA (GenBank accession no. AI563167). From the consensus sequence of this alignment, degenerate PCR primers EREBP forward (5'-AGGGARGCATTACAGAGG-3') and EREBP reverse (5'-GGAAAATTGTNATTGGCCTT-3') were designed to amplify the EREBP domain from an $H$. glycines-infected soybean cDNA library fraction (discussed below). PCR amplification was performed with Taq polymerase (Life Technologies, Gaithersburg, MD, U.S.A.) in a three-temperature program $\left(94,55\right.$, and $72^{\circ} \mathrm{C}$ for $1 \mathrm{~min}$ each) with 30 cycles following a 5min incubation at $94^{\circ} \mathrm{C}$.

cDNA library screening and isolation of cDNA clones.

A Uni-ZAP-XR directionally cloned, oligo-dT-primed cDNA library was constructed (Stratagene, La Jolla, CA, U.S.A.) with RNA prepared from infected 'Corsoy 79' soybean roots harvested at 1,2 , and 3 days postinoculation with the $H$. glycines inbred line OP50 (Dong and Opperman 1997). The radiolabeled PCR fragment containing the EREBP domain was used as a hybridization probe to screen the unamplified library fraction, and positive plaques were isolated, purified, and excised in vivo following the manufacturer's instructions.

\section{DNA sequencing.}

Recombinant plasmids isolated from the soybean root cDNA library were purified by using the Qiagen Plasmid Mini Kit (Qiagen, Chatsworth, CA, U.S.A.) and subjected to sequencing at the Iowa State University DNA Sequencing and Synthesis Facility, Ames, IA, U.S.A.). Sequence analysis was performed with the BLAST and DNASIS programs.

\section{Overexpression of soybean EREBP-like protein.}

The cDNA coding region of the soybean EREBP homolog was cloned into the pET28a vector, which contains a poly-HIS region (Novagen, Madison, WI, U.S.A.) and transformed into the $E$. coli host strain BL21 (DE3) (Novagen). After induction for $1 \mathrm{~h}$ with $1 \mathrm{mM}$ isopropyl- $\beta$-D-thiogalactopyranoside (Research Products International Corp., Mt. Prospect, IL, U.S.A.), cells were harvested. Following resuspension in isolation buffer $(50 \mathrm{mM} \mathrm{NaPO}$, pH 8.0; $300 \mathrm{mM} \mathrm{NaCl})$, lysozyme (Sigma, St. Louis, MO, U.S.A.), proteinase inhibitor cocktail (Sigma), and phenylmethylsulfonyl fluoride (Sigma) were added to final concentrations of $1 \mathrm{mg}$ per $\mathrm{ml}, 2.4 \%$ ( $\mathrm{vol} / \mathrm{vol}$ ), and $2 \mathrm{mM}$, respectively. Cells were incubated on ice for $15 \mathrm{~min}$ 
and then subjected to two freeze-thaw cycles with liquid nitrogen to aid in the cell lysis process. Cellular debris was removed by centrifugation $\left(20,000 \times g, 30 \mathrm{~min}, 4^{\circ} \mathrm{C}\right)$, and the supernatant containing the soluble soybean EREBP-like protein was transferred to a new tube containing $1 \mathrm{ml}$ of prepared (as directed by manufacturer) TALON Metal Affinity Resin (Clontech, Palo Alto, CA, U.S.A.). Resin and protein extract were incubated on ice with frequent mixing for $3 \mathrm{~h}$. Following centrifugation at $500 \times g$ for $5 \mathrm{~min}$ at $4^{\circ} \mathrm{C}$, the resin pellet was washed three times with $15 \mathrm{ml}$ of wash buffer $(50 \mathrm{mM} \mathrm{NaPO}$, $\mathrm{pH}$ 8.0; $300 \mathrm{mM} \mathrm{NaCl} ; 10 \mathrm{mM}$ imidazole). Proteins were eluted from the resin with $1 \mathrm{ml}$ of elution buffer $\left(50 \mathrm{mM} \mathrm{NaPO}_{4}\right.$, $\mathrm{pH} 8.0 ; 300 \mathrm{mM}$ imidazole), aliquoted, and stored at $-80^{\circ} \mathrm{C}$.

GCC box oligonucleotides and mobility-shift assay.

Two pairs of oligonucleotides representing the GCC and mGCC probes were synthesized. The first pair, GCC, contained two GCC boxes in tandem based on the oligo sequences used by Ohme-Takagi and Shinshi (1995) as follows: GCC forward (5'-AATTCATAAGAGCCGCCACTCATAAGAGCCGCCACTCCC $\left.-3^{\prime}\right)$ and GCC reverse (5'-GGGAGTGGCGGCTCTTATGAGTGGCGGCTCTTATG-3'). The second pair, mGCC, represents the mutated GCC in which both $\mathrm{G}$ residues within the GCC box were replaced by $\mathrm{T}$ residues as follows: $\mathrm{mGCC}$ forward (5' - AATTCATAAGATCCTCCACTCATAAGATCCTCCACTCCC- $3^{\prime}$ ) and mGCC reverse (5'-GGGAGTGGAGGATCTTATGAGTGGAGGATCTTATG-3'). Oligos were annealed with their respective partner and labeled with ${ }^{32} \mathrm{P}$-dATP by Klenow end-fill reaction (BioLabs, Beverly, MA, U.S.A.). Probes were purified using Qiaquick Nucleotide Removal Kit (Qiagen) and stored at $-20^{\circ} \mathrm{C}$.

Gel mobility-shift assays were conducted in binding buffer (25 mM $N$-2-hydroxyethylpiperazine- $N$-2-ethanesulfonic acid, $\mathrm{pH} 7.5 ; 20 \mathrm{mM} \mathrm{KCl} ; 10 \%$ glycerol; $0.1 \mathrm{mM}$ EDTA; $0.3 \mathrm{mg}$ of poly-A per $\mathrm{ml}$ ) with approximately $6 \mathrm{ng}$ of purified probe and $6 \mu \mathrm{l}$ of purified protein in a total volume of $10 \mu \mathrm{l}$. After incuba-
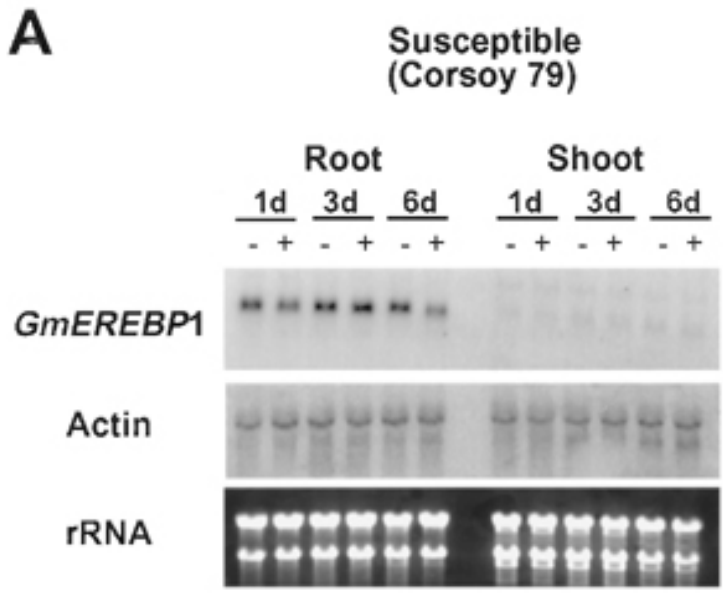

B

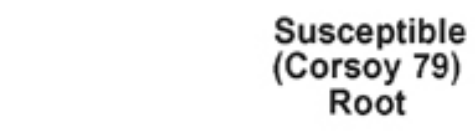

Resistant (Hartwig)
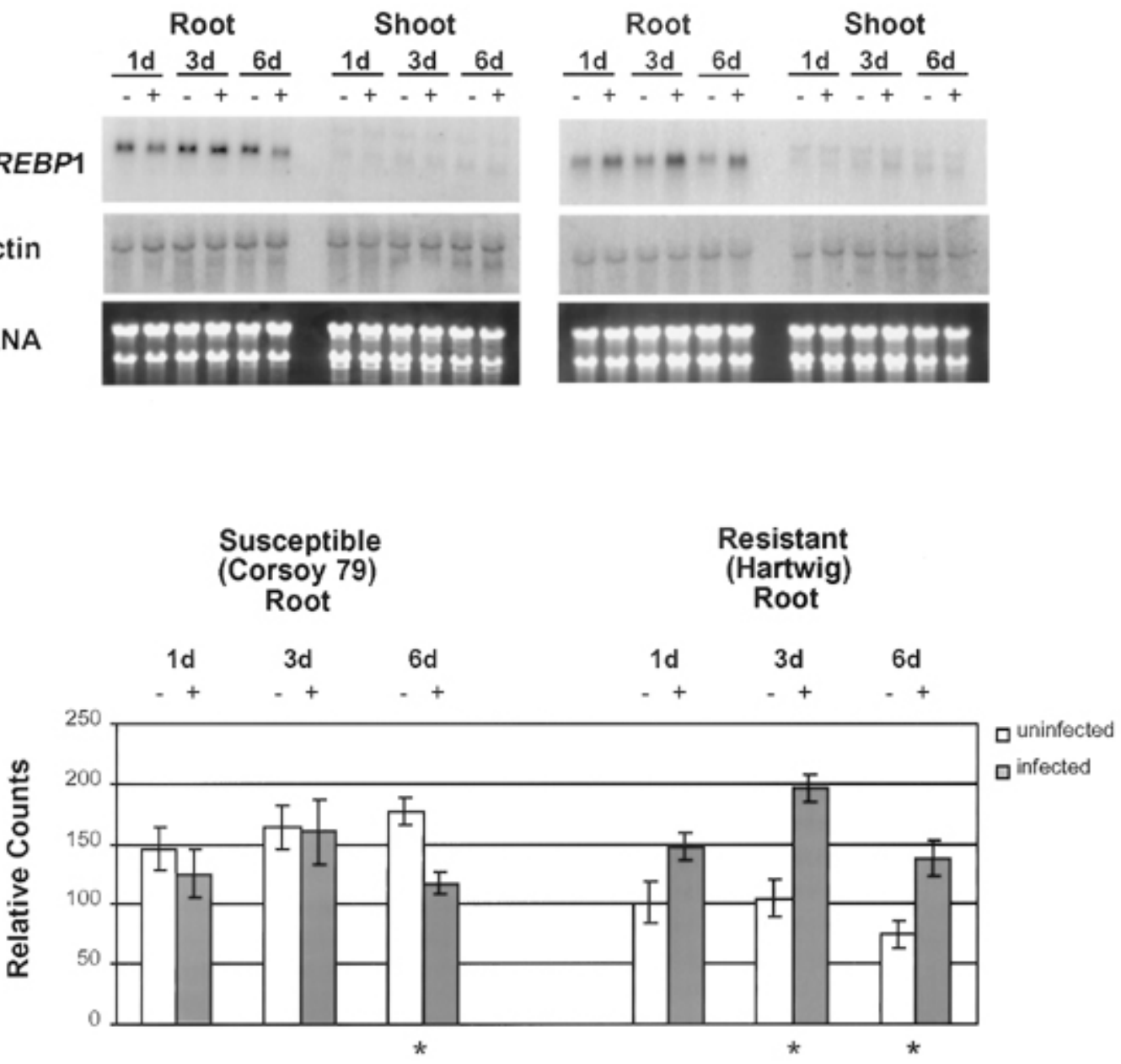

Fig. 5. RNA blot analysis of Glycine max ethylene-responsive element-binding protein 1 (GmEREBP1). A, GmEREBP1 mRNA accumulation in nematodeinfected or uninfected plants of the two soybean cultivars Corsoy 79 (susceptible) and Hartwig (resistant). Blots of total RNA (10 $\mu \mathrm{g}$ per lane) were obtained from roots or shoots of Heterodera glycines-infected (+) and uninfected (-) plants at 1, 3, and 6 days (d) post nematode inoculation. Blots were standardized using an actin probe (Actin), and the ethidium bromide stain of the agarose gel was used to verify equal RNA loading before blotting (rRNA). Autoradiographs were recorded after 3 days of exposure to a phosphorimager screen. Representative blots are shown. Similar results were obtained in three other experiments. B, Quantification of GmEREBP1 expression. Intensity of the hybridization signals detected in the roots of two soybean cultivars were measured with a phosphorimager and quantified with the ImageQuant software. GmEREBP1 hybridization intensity values were adjusted relative to the constitutive actin hybridization intensity values (Relative Counts). Each bar represents the mean of four independent Northern blots with the standard errors of the noted mean. Significance of the repression or induction of GmEREBP1 expression at each time point (infected compared with uninfected) was determined statistically by a two-sample $t$ test $(P<0.05)$. Asterisks indicate significant repression (in susceptible roots) or induction (in resistant roots). 
tion on ice for $15 \mathrm{~min}$, samples were fractionated on $10 \%$ native polyacrylamide gel electrophoresis gels, dried under vacuum, and exposed to film overnight.

\section{Plant and nematode cultivation.}

The H. glycines-susceptible soybean cultivar Corsoy 79 and the $H$. glycines-resistant cultivar Hartwig were used throughout this study. 'Corsoy 79' is susceptible to all tested H. glycines biotypes (Bernard and Cremeens 1998), whereas 'Hartwig', derived from PI 437654, shows a broad-range resistance to $H$. glycines biotypes (Anand 1992; Handoo and Anand 1993; Rao-Arelli et al. 1992). Sterile soybean plants were established by germination of surface-sterilized seeds. Seeds were surface-sterilized by immersion in $70 \%$ ethanol for $5 \mathrm{~min}$ and in $2.1 \%$ sodium hypochlorite for $12 \mathrm{~min}$ and then rinsed three times in sterile distilled water for $10 \mathrm{~min}$. Seeds were germinated in the dark at $26^{\circ} \mathrm{C}$ on $1 \%$ water agar for 2 days, transferred to magenta boxes (Sigma) containing sterile sand supplemented with Hoagland growth solution (Sigma), and grown at $26^{\circ} \mathrm{C}$ with a 16 -h photoperiod of approximately 2,400 Lux provided by fluorescent light bulbs.
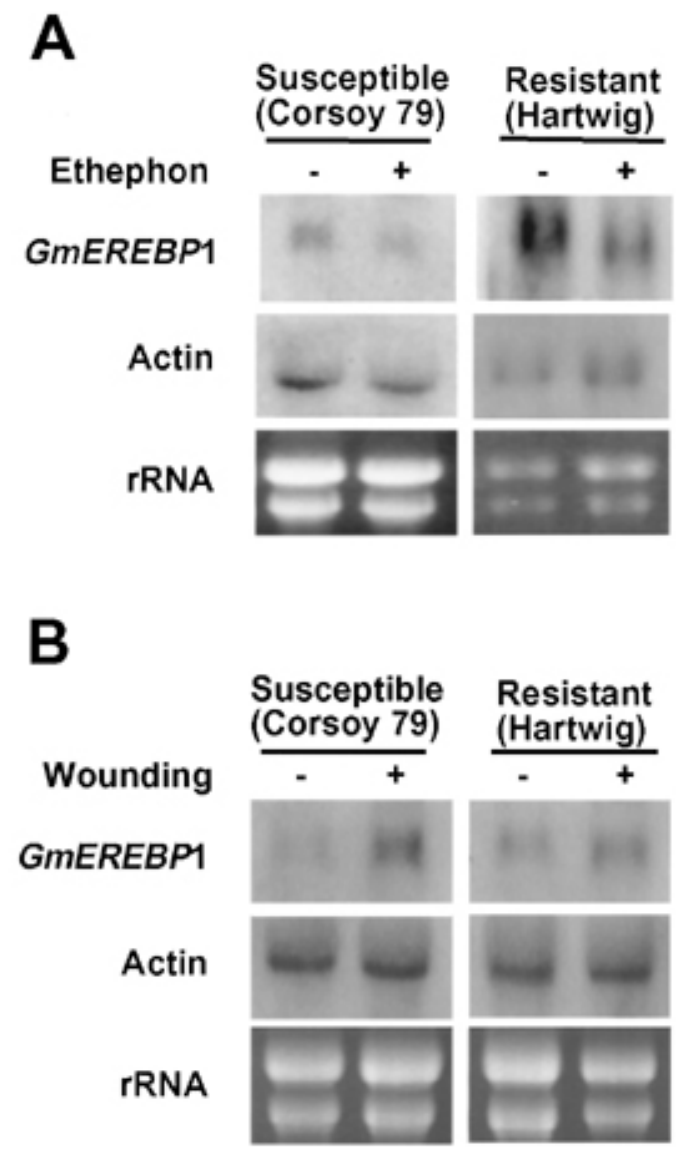

Fig. 6. Effect of ethephon and wounding on expression of Glycine max ethylene-responsive element-binding protein 1 (GmEREBP1). Soybean plants of the two cultivars Corsoy 79 and Hartwig were analyzed after ethephon treatment or wounding. Total RNA was isolated from roots of the treated (+) and untreated (-) plants. Equal RNA loading was verified by visualizing the rRNA in agarose gels stained with ethidium bromide. Each lane contained $10 \mu \mathrm{g}$ of RNA. (The different staining intensities between 'Corsoy 79' and 'Hartwig' rRNA are due to varying exposure times during photography of the agarose gels.) An actin probe was used to standardize the blots. The exposure time for all blots was 3 days. A, Ethephon treatment. The soybean plants were incubated in $1 \mathrm{mM}$ ethephon in $50 \mathrm{mM}$ phosphate buffer, $\mathrm{pH} 7.0$, for $24 \mathrm{~h}$ or in the buffer alone as a control. B, Wounding. The soybean plants were wounded by piercing the root tissues with a scalpel. The wounded plants were incubated on filter paper moistened with $50 \mathrm{mM}$ phosphate buffer, $\mathrm{pH} 7.0$, for $24 \mathrm{~h}$. Control plants were incubated under the same conditions without wounding.
The $H$. glycines inbred line OP50 was propagated in greenhouse cultures using 'Corsoy 79' soybeans as hosts. Infective juveniles (J2) were prepared from these nematode cultures for plant inoculations by using standard nematology methodology as described by Hermsmeier and colleagues (1998). Inoculated soybean roots were examined for nematode infection and developmental stages at varying time points after inoculation by staining with acid fuchsin following the procedure of Hussey (1990). Stained nematodes were examined with a dissecting microscope.

\section{Plant inoculation and tissue harvesting.}

Nematodes for soybean root inoculation were surface-sterilized for $12 \mathrm{~min}$ in $0.01 \%$ mercuric chloride and then washed three times in sterile distilled water. Nematodes were pelleted and then resuspended in 1.5\% low-melting-point agarose (Life Technologies) at $37^{\circ} \mathrm{C}$. Plants were inoculated at the two-trueleaf stage after approximately 8 days of growth in the sandfilled magenta boxes. Inoculation was performed by applying $1 \mathrm{ml}$ of the agarose-nematode suspension, containing about 1,000 nematodes, to plant rooting zones via narrow holes created in the sand substrate prior to inoculation. Control plants received agarose without nematodes. Plants were allowed to continue growth as described above. At different time points after inoculation, plants were taken out of the sand, and their roots were washed by rinsing with sterile distilled water. Root and shoot (including cotyledons and two-true-leaves) tissues of eight plants per treatment were harvested at each time point, frozen in liquid nitrogen, and stored at $-80^{\circ} \mathrm{C}$ until use. At each time point of tissue harvest, samples of infected roots were stained to verify nematode infection and to assess nematode development. To ensure aseptic conditions, the agarose-nematode suspension used for plant inoculation was also applied to sterile soybean plants established on Gamborg's B5 medium (Life Technologies). These cultures were monitored for signs of microbial contamination. An inoculation series that remained clear of microbial contamination was used for the RNA blot data presented in this manuscript.

\section{Ethephon and wounding treatments.}

Soybean plants were grown in soil (Sunshine Universal Mix; Consumer Supply, Storm Lake, IA, U.S.A.), under the same temperature and lighting regimes mentioned above. Treatments were performed on 8-day-old plants. The root systems of whole plants were washed gently with water to remove soil and then the plants were used for each treatment. Root and shoot (including cotyledons and two-true-leaves) tissues of 10 plants per treatment were harvested, frozen in liquid nitrogen, and kept at $-80^{\circ} \mathrm{C}$ until use.

For ethephon assays, the whole plants were incubated for $24 \mathrm{~h}$ in $1 \mathrm{mM}$ ethephon (2-chloroethylphosphonic acid) (Sigma), an ethylene-releasing chemical, in $50 \mathrm{mM}$ phosphate buffer, $\mathrm{pH}$ 7.0 , or in the buffer alone as a control. As recommended by Ohme-Takagi and Shinshi (1995), the buffer was used to avoid the effect of the acids release during the breakdown of ethephon.

Wounding was performed by repeatedly piercing the roots of whole plants with a scalpel. The wounded plants were incubated for $24 \mathrm{~h}$ on filter paper moistened with $50 \mathrm{mM}$ phosphate buffer, pH 7.0. Control plants were incubated under the same conditions in the absence of wounding.

\section{RNA and DNA gel blot analyses.}

Total RNA was isolated from frozen root and shoot tissues ground under liquid nitrogen as described by Pawlowski and colleagues (1994). Ten micrograms of RNA per sample was separated on $1 \%$ formaldehyde agarose gels and transferred to 
nylon membranes (S\&S Nytran Plus; Schleicher \& Schuell, Keene, NH, U.S.A.) by a wet blotting procedure (Sambrook et al. 1989). RNA was fixed to the membranes with a FB-UVXL1000 crosslinker (Fisher Scientific, Pittsburgh, PA, U.S.A.). For the nematode experiments, a total of four independent blots was prepared from the total RNAs of each susceptible and resistant response.

The soybean EREBP-like cDNA was amplified by PCR with vector-specific primers T3 and T7 (Integrated DNA Technology Inc., Coralville, IA, U.S.A.), gel purified with the Qiaex II Kit (Qiagen), radiolabeled via PCR, and then used as a probe in RNA blot analyses. Hybridizations were carried out at $42^{\circ} \mathrm{C}$ in a hybridization buffer composed of $5 \times \mathrm{SSC}(1 \times \mathrm{SSC}$ is $0.15 \mathrm{M}$ $\mathrm{NaCl}$ plus $0.015 \mathrm{M}$ sodium citrate), $50 \%$ formamide, $0.1 \%$ sodium dodecyl sulfate (SDS), $5 \times$ Denhardt's solution (Sambrook et al. 1989), $0.1 \mathrm{mg}$ of herring-sperm DNA per ml, and $3 \times 10^{6}$ $\mathrm{cpm} / \mathrm{ml}$ of labeled gene probe. The hybridized blots were washed three times for $15 \mathrm{~min}$ in $0.1 \times \mathrm{SSC} / 0.1 \% \mathrm{SDS}$ at $65^{\circ} \mathrm{C}$. Bound radiolabeled probes were imaged with a Molecular Dynamics Storm840 PhosphorImager (Molecular Dynamics, Sunnyvale, CA, U.S.A.), which allowed quantification of hybridized probe by using the ImageQuant software (Molecular Dynamics).

A blot of EcoRI-digested soybean genomic DNA was prepared as described by Hermsmeier and colleagues (1998). DNA gel blot hybridization and analysis was performed as explained above.

\section{ACKNOWLEDGMENTS}

This is journal paper no. 19720 of the Iowa Agriculture and Home Economics Experiment Station, Ames, IA, project no. 3381, and supported by Hatch Act and State of Iowa funds. We gratefully acknowledge funding by the Iowa Soybean Promotion Board and USDA-NRICGP award \#99-35302-7938. We thank T. R. Maier for technical assistance and A. Bogdanove and M. R. Hajimorad for review of the manuscript.

\section{LITERATURE CITED}

Altschul, S. F., Madden, T. L., Schaffer, A. A., Zhang, J., Zhang, Z., Miller, W., and Lipman, D. J. 1997. Gapped BLAST and PSI-BLAST: A new generation of protein database search program. Nucleic Acids Res. 25:3389-3402.

Anand, S. C. 1992. Registration of "Hartwig" soybean. Crop Sci. 32: 1069-1070.

Bernard, R. L., and Cremeens, C. R. 1998. Registration of "Corsoy 79" soybean. Crop Sci. 28:1027.

Büttner, M., and Singh, K. B. 1997. Arabidopsis thaliana ethylene-responsive element binding protein (AtEBP), an ethylene-inducible, GCC box DNA-binding protein interacts with an ocs element binding protein. Proc. Natl. Acad. Sci. U.S.A. 94:5961-5966.

Davis, E. L., Hussey, R. S., Baum, T. J., Bakker, J., Schots, A., Rosso, M. N., and Abad, P. 2000. Nematode parasitism genes. Annu. Rev. Phytopathol. 38:365-396.

Dong, K., and Opperman, C. H. 1997. Genetic analysis of parasitism in the soybean cyst nematode Heterodera glycines. Genetics 146:13111318.

Endo, B. Y. 1991. Ultrastructure of initial responses of susceptible and resistant soybean roots to infection by Heterodera glycines. Rev. Nematol. 14:73-94.

Finkelstein, R. R., Wang, M. L., Lynch, T. J., Rao, S., and Goodman, H. M. 1998. The Arabidopsis abscisic acid response locus ABI4 encodes an APETAL2 domain protein. Plant Cell 10:1043-1054.

Fujimoto, S. Y., Ohta, M., Usui, A., Shinshi, H., and Ohme-Takagi, M. 2000. Arabidopsis ethylene-responsive element binding factors act as transcriptional activators or repressors of GCC box-mediated gene expression. Plant Cell 12:393-404.

Glazer, I., Epstein, E., Orion, D., and Apelbaum, A. 1986. Interactions between auxin and ethylene in root-knot nematode (Meloidogyne javanica) infected tomato roots. Physiol. Mol. Plant Pathol. 28:171-179.

Gu, Y. Q., Yang, C., Thara, V. K., Zhou, J., and Martin, G. B. 2000. Pti4 is induced by ethylene and salicylic acid, and its product is phosphorylated by the Pto kinase. Plant Cell 12:771-785.
Handoo, Z. A., and Anand, S. C. 1993. Biological manifestation of resistance to soybean cyst nematode development in Hartwig soybean. Crop Prot. 12:371-372.

Hermsmeier, D., Mazarei, M., and Baum, T. J. 1998. Differential display analysis of the early compatible interaction between soybean and the soybean cyst nematode. Mol. Plant-Microbe Interact. 11:1258-1263.

Hermsmeier, D., Hart, J. K., Byzova, M., Rodermel, S. R., and Baum, T. J. 2000. Changes in mRNA abundance within Heterodera schachtiiinfected roots of Arabidopsis thaliana. Mol. Plant-Microbe Interact. 13:309-315.

Hussey, R. S. 1990. Staining nematodes in plant tissue. Pages 190-193 in: Plant Nematology Laboratory Manual. B. M. Zuckerman, W. F. Mai, and L. R. Krusberg, eds. The University of Massachusetts Agricultural Experiment Station, Amherst, MA, U.S.A.

Johnson, P. R., and Ecker, J. R. 1998. The ethylene gas signal transduction pathway: A molecular perspective. Annu. Rev. Genet. 32:227-254.

Jones, M. G. K. 1981. Host cell responses to endoparasitic nematode attack: Structure and function of giant cells and syncytia. Ann. Appl. Biol. 97:353-372.

Kagaya, Y., Ohmiya, K., and Hattori, T. 1999. RAV1, a novel DNA-binding protein, binds to bipartite recognition sequence through two distinct DNA-binding domains uniquely found in higher plants. Nucleic Acid Res. 27:470-478.

Kim, K. S., and Riggs, R. D. 1992. Cytopathological reactions of resistant soybean plants to nematode invasion. Pages 157-168 in: Biology and Management of the Soybean Cyst Nematode. R. D. Riggs and J. A. Wrather, eds. American Phytopathological Society, St. Paul, MN, U.S.A.

Kim, Y. H., Riggs, R. D., and Kim, K. S. 1987. Structural changes associated with resistance of soybean to Heterodera glycines. J. Nematol. 19:177-187.

Latchman, D. S. 1995. Eukaryotic Transcription Factors. 2nd ed. Academic Press, San Diego, CA, U.S.A.

Liu, Q., Kasuga, M., Sakuma, Y., Abe, H., Miura, S., YamaguchiShinozaki, K., and Shinozaki, K. 1998. Two transcription factors, DREB1 and DREB2, with an EREBP/AP2 DNA binding domain, separate two cellular signal transduction pathways in drought- and low temperature-responsive gene expression, respectively, in Arabidopsis. Plant Cell 10:1391-1406.

Mahalingam, R., and Skorupska, H. T. 1996. Cytological expression of early response to infection by Heterodera glycines Ichinohe in resistant PI 437654 soybean. Genome 39:986-996.

Mahalingam, R., Wang, G., and Knap, H. T. 1999. Polygalacturonase and polygalacturonase inhibitor protein: Gene isolation and transcription in Glycine max-Heterodera glycines interactions. Mol. Plant-Microbe Interact. 12:490-498.

Menke, F. L. H., Champion, A., Kijne, J. W., and Memelink, J. 1999. A novel jasmonate- and elicitor-responsive element in the periwinkle secondary metabolite biosynthetic gene Str interacts with a jasmonateand elicitor-inducible AP2-domain transcription factor, ORCA2. EMBO (Eur. Mol. Biol. Organ.) J. 18:4455-4463.

Nagao, R. T., Shah, D. M., Eckenrode, V. K., and Meagher, R. B. 1981. Multigene family of actin-related sequences isolated from a soybean genomic library. DNA 2:1-9.

Ohme-Takagi, M., and Shinshi, H. 1995. Ethylene-inducible DNA binding proteins that interact with an ethylene-responsive element. Plant Cell 7:173-182.

Ohta, M., Ohme-Takagi, M., and Shinshi, H. 2000. Three ethylene-responsive transcription factors in tobacco with distinct transactivation functions. Plant J. 22:29-38.

Ohta, M., Matsui, K., Hiratsu, K., Shinshi, H., and Ohme-Takagi, M. 2001. Repression domains of class II ERF transcriptional repressors share an essential motif for active repression. Plant Cell 13:1959-1968.

Okamuro, J. K., Caster, B., Villarroel, R., Van Montagu, M., and Jofuku, K. D. 1997. The AP2 domain of APETAL2 defines a large new family of DNA binding proteins in Arabidopsis. Proc. Natl. Acad. Sci. U.S.A. 94:7076-7081.

Park, J. M., Park, C., Lee, S., Ham, B., Shin, R., and Paek, K. 2001. Overexpression of the tobacco Tsil gene encoding an EREBP/AP2type transcription factor enhances resistance against pathogen attack and osmotic stress in tobacco. Plant Cell 13:1035-1046.

Pawlowski, K., Kunze, R., De Vries, S., and Bisseling, T. 1994. Isolation of total, poly(A) and polysomal RNA from plant tissues. Pages D5/1D5/13 in: Plant Molecular Biology Manual. S. B. Gelvin and R. A Schilperoort, eds. Kluwer Academic, Dordrecht, The Netherlands.

Raikhel, N. 1992. Nuclear targeting in plants. Plant Physiol. 100:1627-1632.

Rao-Arelli, A. P., Wrather, J. A., and Anand, S. C. 1992. Genetic diversity among isolates of Heterodera glycines and sources of resistance in soybeans. Plant Dis. 76:894-896.

Riechmann, J. L., and Meyerowitz, E. M. 1998. The AP2/EREBP family 
of plant transcription factors. Biol. Chem. 379:633-646.

Sambrook, J., Fritsch, E. F., and Maniatis, T. A. 1989. Molecular Cloning: A Laboratory Manual. 2nd ed. Cold Spring Harbor Laboratory, Cold Spring Harbor, NY, U.S.A.

Solano, R., Stepanova, A., Chao, Q., and Ecker, J. R. 1998. Nuclear events in ethylene signalling: A transcriptional cascade mediated by ETHYLENE-INSENSITIVE3 and ETHYLENE-RESPONSE-FACTOR1. Genes Dev. 12:3703-3714.

Stepanova, A. N., and Ecker, J. R. 2000. Ethylene signaling: From mutants to molecules. Curr. Opin. Plant Biol. 3:353-360.

Stockinger, E. J., Gilmour, S. J., and Thomashow, M. F. 1997. Arabidopsis thaliana $C B F 1$ encodes an AP2 domain-containing transcriptional activator that binds to the C-repeat/DRE, a cis-acting DNA regulatory element that stimulates transcription in response to low temperature and water deficit. Proc. Natl. Acad. Sci. U.S.A. 94:1035-1040.

Thara, V. K., Tang, X., Gu, Y. Q., Martin, G. B., and Zhou, J. M. 1999. Pseudomonas syringae pv. tomato induces the expression of tomato EREBP-like genes Pti4 and Pti5 independent of ethylene, salicylate and jasmonate. Plant J. 20:475-483.

Thompson, J. D., Higgins, D. G., and Gibson, T. J. 1994. CLUSTAL W: Improving the sensitivity of progressive multiple sequence alignment through sequence weighting, position-specific gap penalties and weight matrix choice. Nucleic Acids Res. 22:4673-4680.

Vaghchipawala, Z., Bassüner, R., Clayton, K., Lewers, K., Shoemaker, R., and Mackenzie, S. 2001. Modulations in gene expression and mapping of genes associated with cyst nematode infection of soybean. Mol. Plant-Microbe Interact. 14:42-54 van der Fits, L., and Memelink, J. 2000. ORCA3, a jasmonate-responsive transcriptional regulator of plant primary and secondary metabolism. Science 289:295-297.

Volkmar, K. M. 1991. Abscisic acid and ethylene increase in Heterodera avenae-infected tolerant or intolerant oat cultivars. J. Nematol. 23 425-431.

Williamson, V. M., and Hussey, R. S. 1996. Nematode pathogenesis and resistance in plants. Plant Cell 8:1735-1745.

Wilson, K., Long, D., Swinburne, J., and Coupland, G. 1996. A dissociation insertion causes a semidominant mutation that increases expression of TINY, an Arabidopsis gene related to APETAL2. Plant Cell 8: 659-671.

Wrather, J. A., Anderson, T. R., Arsyad, D. M., Tan, Y., Ploper, L. D., Porta-Puglia, A., Ram, H. H., and Yorinori, J. T. 2001a. Soybean disease loss estimates for the top ten soybean-producing countries in 1998. Can. J. Plant Pathol. 23:115-121.

Wrather, J. A., Stienstra, W. C., and Koenning, S. R. 2001b. Soybean disease loss estimates for the United States from 1996 to 1998. Can. J. Plant Pathol. 23:122-131.

Xu, P., Narasimhan, M. L., Samson, T., Coca, M. A., Huh, G., Zhou, J., Martin, G. B., Hasegawa, P. M., and Bressan, R. A. 1998. A nitrilaselike protein interacts with GCC box DNA-binding proteins involved in ethylene and defense responses. Plant Physiol. 118:867-874.

Zhou, J., Tang, X., and Martin, G. B. 1997. The Pto kinase conferring resistance to tomato bacterial speck disease interacts with proteins that bind a cis-element of pathogenesis-related genes. EMBO (Eur. Mol. Biol. Organ.) J. 16:3207-3218. 